\title{
Diesterase Activity and Substrate Binding in Purple Acid Phosphatases
}

\author{
Robynn S. Cox, ${ }^{\dagger}$ Gerhard Schenk, ${ }^{*} \S$ Nataša Mitic,, Lawrence R. Gahan,, and Alvan C. Hengge ${ }^{*} \dagger$ \\ Department of Chemistry and Biochemistry, Utah State University, Logan, Utah 84322-0300, and School of \\ Molecular and Microbial Sciences, University of Queensland, Brisbane 4072, Australia
}

Received April 16, 2007; E-mail: hengge@cc.usu.edu

Purple acid phosphatases (PAPs) are dinuclear monoesterases ${ }^{1,2}$ that are structurally diverse but with a conserved set of ligands to the $\mathrm{Fe}^{3+}-\mathrm{M}^{2+}$ metal centers $\left(\mathrm{M}^{2+}=\mathrm{Fe}, \mathrm{Zn}\right.$, or $\left.\mathrm{Mn}\right) .^{3}$ The identity of the nucleophile and the substrate binding mode have been matters of controversy (Figure 1). ${ }^{1,3-5}$ In one proposal, substrate binds to the divalent metal and is attacked by a terminal $\mathrm{Fe}^{3+}$-bound hydroxide. In an alternative mechanism, substrate coordinates first to the divalent metal and then forms a bridging complex, followed by nucleophilic attack by the $\mu$-hydroxide. We report that the PAPs from pig and kidney bean catalyze the hydrolysis of diesters if the second ester group is small, and the kinetics of the reaction with methyl $p$-nitrophenylphosphate suggest that a terminal-bound hydroxide is the nucleophile for the diester, followed by attack of the bridging hydroxide upon the resulting monoester without release into solution.

The PAPs are reported to lack the ability to hydrolyze diesters, based on the lack of activity with bis( $p$-nitrophenyl)phosphate (BpNPP). ${ }^{6}$ In contrast, model complexes designed to mimic the PAP metal center hydrolyze diesters, while monoesterase activity has not been reported. ${ }^{7}$ This suggests that the inability of PAP to hydrolyze BpNPP might result from steric considerations. Thus, we tested the PAPs from pig (also termed uteroferrin) and from red kidney bean using two diesters bearing smaller second ester groups, methyl pNPP (MpNPP) and ethyl pNPP (EpNPP). While BpNPP gave negligible turnover, consistent with a previous report, ${ }^{6}$ the other two diesters, particularly MpNPP, are substrates although binding is poor. The $\mathrm{pH}$ dependence for $k_{\mathrm{cat}}$ and $k_{\mathrm{cat}} / K_{\mathrm{m}}$ of the reactions with MpNPP was followed by monitoring release of p-nitrophenol (see Supporting Information, Figure S1). The $\mathrm{pH}$ optima for monoesterase and diesterase reactions were the same; data in Table 1 were obtained at the optimal $\mathrm{pH}$ of 4.9 for pig $\mathrm{PAP}$ and $\mathrm{pH} 6.25$ for kbPAP (see Supporting Information for EpNPP and BpNPP data).

At its $\mathrm{pH}$ optimum, the $k_{\text {cat }}$ for MpNPP hydrolysis by pig PAP is close to that for the monoester pNPP, 5,8 while for kbPAP, the MpNPP $k_{\text {cat }}$ is about half that for pNPP.

The high diester $K_{\mathrm{m}}$ values presumably result from steric requirements of the second ester group. ${ }^{14}$ For comparison, $K_{\mathrm{m}}$ values of aryl and benzyl monoesters range from 1.25 to $5.8 \mathrm{mM}^{5}$ Inorganic phosphate is a competitive inhibitor of the reactions of both PAPs with MpNPP, with $K_{\mathrm{i}}$ values close to the literature values for the reactions with pNPP (Table 2).

The reaction of MpNPP is assumed to first yield $p$-nitrophenol and methyl phosphate, on the basis of the large difference in the $\mathrm{p} K_{\mathrm{a}}$ values of the two potential leaving groups and the observation that PAP catalysis shows a significant dependence on the leaving group ( $\beta_{\mathrm{lg}}=-0.4$ and -0.6 for pig and kbPAP, respectively). ${ }^{5}$ Methyl phosphate (MP), the presumed product of the diester reaction, is a substrate, with $k_{\text {cat }}$ values of 17 and $20 \mathrm{~s}^{-1}$ for the pig

Utah State University.

$\S$ University of Queensland.

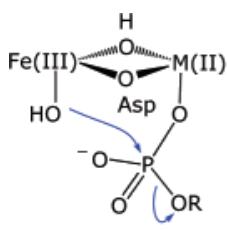

A

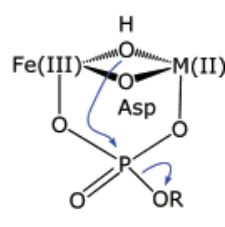

B
Figure 1. Schematic diagram of two potential binding modes of a phosphate ester to the metal center of PAPs. In A, the nucleophile is the Fe(III)coordinated hydroxide; in $\mathrm{B}$, it is a bridging $\mu$-hydroxide.

Table 1. Kinetic Data for PAP Hydrolysis of Methyl $p$-Nitrophenyl Phosphate (MpNPP), Methyl Phosphate (MP), and $p$-Nitrophenyl Phosphate (pNPP) by Pig PAP (red) and kbPAP (blue) (Standard Errors are Shown in Parentheses)

\begin{tabular}{llll}
\hline & $\mathrm{K}_{\mathrm{m}}(\mathrm{mM})$ & $\mathrm{k}_{\mathrm{cat}}\left(\mathrm{s}^{-1}\right)$ & $\mathrm{k}_{\mathrm{cat}} / \mathrm{K}_{\mathrm{m}}\left(\mathrm{mM}^{-1} \mathrm{~s}^{-1}\right)$ \\
\hline MpNPP & $110(18)$ & $542(91)$ & 4.9 \\
MP & $138(10)$ & $17(1)$ & 0.12 \\
pNPP & $1.25(0.25)$ & $470(40)$ & 380 \\
MpNPP & $356(70)$ & $542(24)$ & 1.5 \\
MP & $281(47)$ & $20(3)$ & 0.07 \\
pNPP $^{5},{ }^{9}$ & $2.2(0.1), 3.7(0.2)$ & $850(30), 944(68)$ & 390,244 \\
\hline
\end{tabular}

Table 2. Inhibition Data

\begin{tabular}{lll}
\hline & $\mathrm{K}_{\mathrm{i}}(\mathrm{mM})$ vs. pNPP & $\mathrm{K}_{\mathrm{i}}(\mathrm{mM})$ vs. MpNPP \\
\hline Inorganic phosphate & $2^{10}$ & $4.1(0.9)$ \\
MP & $106(11)$ & $108(22)$ \\
Inorganic phosphate & $1.8^{11}$ & $0.8(0.3)$ \\
MP & $104(15)$ & $103(11)$ \\
\hline
\end{tabular}

and kbPAPs respectively, with surprisingly high $K_{\mathrm{m}}$ values (Table 1). MP is a weak competitive inhibitor of the PAP-catalyzed hydrolysis of pNPP and of MpNPP, with a $K_{\mathrm{i}}$ of $\sim 100 \mathrm{mM}$ (Table 2). These $K_{\mathrm{i}}$ values confirm the unexpectedly weak binding of MP. As noted above, previously characterized substrates with low millimolar $K_{\mathrm{m}}$ values are aryl and benzyl esters. It may be that the PAP active site region recognizes the aromatic moiety in these substrates. Studies of PAP inhibitors have shown that aromatic groups are important in achieving tight binding. ${ }^{8}$

In the MpNPP reactions, the rates of formation of $p$-nitrophenol and of inorganic phosphate decreased significantly after only a few percent of the diester was consumed (see Figure 2 and Supporting Information). Addition of pNPP immediately resulted in rapid production of $p$-nitrophenol, showing that this was not due to loss of enzymatic activity (see Supporting Information for details). The low $K_{\mathrm{i}}$ for inorganic phosphate and high $K_{\mathrm{m}}$ of the diester leads to the expectation of significant product inhibition. This was confirmed by an experiment in which enzyme was preincubated with an amount of inorganic phosphate corresponding to that produced after the first $5 \%$ of reaction. Addition of MpNPP substrate gave rise to the same slow rate observed after $\sim 5 \%$ had been turned over in the experiments without preincubation with phosphate. 


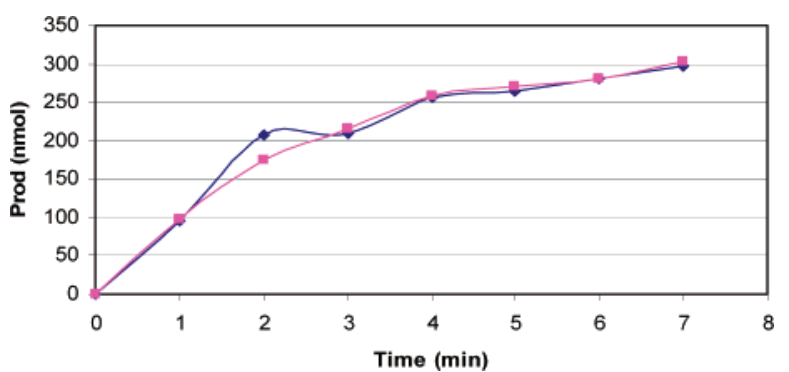

Figure 2. The rates of formation of inorganic phosphate (ם) and of $p$-nitrophenol ( ) from a reaction of pig PAP initiated with $15 \mathrm{mM}$ MpNPP in $0.1 \mathrm{M}$ acetate buffer at $\mathrm{pH} 4.90$ at $22{ }^{\circ} \mathrm{C}$. Enzyme concentration was 13 $\mathrm{nM}$, in a reaction volume of $500 \mu \mathrm{L}$. Similar results were obtained with kbPAP (see Supporting Information).

In the reactions of MpNPP, the production of inorganic phosphate and of $p$-nitrophenol were followed to determine whether the two reactions are processive (proceeding from a single binding event) or whether methyl phosphate is released into solution prior to rebinding and hydrolysis. MpNPP and MP have similar a $K_{\mathrm{m}}$, and MP has a much lower $k_{\text {cat }} / K_{\mathrm{m}}$. Thus, if the MP product is released, then its recapture and hydrolysis to inorganic phosphate should lag behind the formation of $p$-nitrophenol in the initial stages of the reaction when $[\mathrm{MpNPP}] \gg[\mathrm{MP}]$. In a reaction with an initial concentration of $15 \mathrm{mM} \mathrm{MpNPP}$, the rates of formation of $p$-nitrophenol and of inorganic phosphate were indistinguishable (Figure 2). This observation is most consistent with a reaction mechanism in which the diester is converted to the monoester, which is then hydrolyzed to inorganic phosphate without being released.

The kinetic results pose an apparent conundrum: the consecutive turnover of MpNPP followed by MP occurs with a turnover number significantly higher than that for MP alone. We propose that this is a result of the manner in which the monoester substrate is formed at the active site and reveals information about how the monoester binds when it is provided as a free substrate in solution.

In the PAP model systems, diesters are proposed to coordinate to the divalent metal and undergo attack by an Fe(III)-coordinated hydroxide. ${ }^{7}$ If the diester reacts in this manner in the PAP reactions, as shown in A of Figure 1, then nucleophilic attack will result in a bidentately bound monoester, immediately poised for attack by the bridging hydroxide. Alternatively, if the diester binds in a bidentate fashion, attack by the bridging hydroxide would produce a tripodally coordinated intermediate, which could rapidly add water from solvent to yield a bridging monoester complex (precedent for such a process comes from the reactions of phosphodiesters bound to a di-Co ${ }^{3+}$ complex). ${ }^{12}$

While the second possibility cannot be ruled out, we propose that the first alternative is more consistent with the kinetic data and with previous observations. Phosphodiesters bind and undergo hydrolysis by PAP model systems in the manner we propose for the enzymatic reaction. Also, it has been shown that coordination of inorganic phosphate to the active site of pig PAP takes place by rapid binding to $\mathrm{Fe}^{2+}$ followed by rate-determining bridging to $\mathrm{Fe}^{3+}$. The second step is significantly slower when the $\mathrm{Fe}^{3+}$ ligand to be displaced is hydroxide rather than water $\left(\mathrm{p} K_{\mathrm{a}}=\right.$ 3.8). ${ }^{13}$

We propose that the PAP diesterase reactions occur by a processive mechanism, whereby monodentate coordination of the substrate occurs (Figure 1A), with subsequent hydrolysis of the first ester bond by the terminal $\mathrm{Fe}^{3+}$-bound hydroxide. This forms MP at the active site poised for immediate and subsequent attack by the $\mu$-hydroxide (Figure 1B). When free MP is the substrate, turnover may be partially limited by the displacement of hydroxide from $\mathrm{Fe}^{3+}$ to form the bidentate complex.

While the requirement for a very small second ester group for diesterase activity means that this activity has no biological relevance, the results reveal that the metal centers in pig and kbPAP have similar inherent catalytic competence in both monoesterase and diesterase hydrolysis, a capability that has not been reported in model systems.

Acknowledgment. This work was supported by a grant to A.H. from the NIH (GM47297). G.S. and L.G. wish to thank the Australian Research Council for funding (DP0558652). We thank members of the Hengge lab for comments on the manuscript.

Supporting Information Available: Experimental procedures, kinetic methods, $\mathrm{pH}$ profiles, and kinetic data. This material is available free of charge via the Internet at http://pubs.acs.org.

\section{References}

(1) Sträter, N.; Lipscomb, W. N.; Klabunde, T.; Krebs, B. Angew. Chem., Int. Ed. Engl. 1996, 35, 2024-2055.

(2) (a) Wilcox, D. E. Chem. Rev. 1996, 96, 2435-2458. (b) Mitić, N.; Smith, S. J.; Neves, A.; Guddat, L. W.; Gahan, L. R.; Schenk, G. Chem. Rev. 2006, 106, 3338-3363. (c) Vincent, J. B.; Olivier-Lilley, G. L.; Averill, B. A. Chem. Rev. 1990, 90, 1447-1467.

(3) Schenk, G.; Boutchard, C. L.; Carrington, L. E.; Noble, C. J.; Moubaraki, B.; Murray, K. S.; de Jersey, J.; Hanson, G. R.; Hamilton, S. J. Biol. Chem. 2001, 276, 19084-19088.

(4) (a) Merkx, M.; Averill, B. A. J. Am. Chem. Soc. 1999, 121, 6683-6689. (b) Merkx, M.; Pinkse, M. W.; Averill, B. A. Biochemistry 1999, 38 , 9914-9925. (c) Smoukov, S. K.; Quaroni, L.; Wang, X.; Doan, P. E.; Hoffman, B. M.; Que, L., Jr. J. Am. Chem. Soc. 2002, 124, 2595-2603. (d) Klabunde, T.; Sträter, N.; Frohlich, R.; Witzel, H.; Krebs, B. J. Mol. Biol. 1996, 259, 737-748. (e) Pinkse, M. W.; Merkx, M.; Averill, B. A. Biochemistry 1999, 38, 9926-9936.

(5) Schenk, G.; Gahan, L. R.; Carrington, L. E.; Mitić, N.; Valizadeh, M.; Hamilton, S. E.; de Jersey, J.; Guddat, L. W. Proc. Natl. Acad. Sci. U.S.A. 2005, 102, 273-278.

(6) Schlosnagle, D. C.; Bazer, F. W.; Tsibris, J. C.; Roberts, R. M. J. Biol. Chem. 1974, 249, 7574-7579.

(7) (a) Lanznaster, M.; Neves, A.; Bortoluzzi, A. J.; Szpoganicz, B.; Schwingel, E. Inorg. Chem. 2002, 41, 5641-5643. (b) Karsten, P.; Neves, A.; Bortoluzzi, A. J.; Lanznaster, M.; Drago, V. Inorg. Chem. 2002, 41, 4624-4626. (c) Batista, S. C.; Neves, A.; Bortoluzzi, A. J.; Vencato, I.; Peralta, R. A.; Szpoganicz, B.; Aires, V. V. E.; Terenzi, H.; Severino, P. C. Inorg. Chem. Commun. 2003, 6, 1161-1165.

(8) Valizadeh, M.; Schenk, G.; Nash, K.; Oddie, G. W.; Guddat, L. W.; Hume, D. A.; de Jersey, J.; Burke, T. R., Jr.; Hamilton, S. Arch. Biochem. Biophys. 2004, 424, 154-162.

(9) Truong, N. T.; Naseri, J. I.; Vogel, A.; Rompel, A.; Krebs, B. Arch Biochem. Biophys. 2005, 440, 38-45.

(10) Keough, D. T.; Beck, J. L.; de Jersey, J.; Zerner, B. Biochem. Biophys Res. Commun. 1982, 108, 1643-1648.

(11) Cashikar, A. G.; Rao, N. M. J. Biol. Chem. 1996, 271, 4741-4746.

(12) Williams, N. H.; Lebuis, A.-M.; Chin, J. J. Am. Chem. Soc. 1999, 121, $3341-3348$

(13) (a) Aquino, M. A. S.; Lim, J.-S.; Sykes, A. G. J. Chem. Soc., Dalton Trans. 1994, 429-436. (b) Aquino, M. A. S.; Lim, J. S.; Sykes, A. G. J. Chem. Soc., Dalton Trans. 1992, 2135-2136. (c) Twitchett, M. B.; Schenk, G.; Aquino, M. A. S.; Yiu, D. T. Y.; Lau, T. C.; Sykes, A. G. Inorg. Chem. 2002, 41, 5787-5794.

(14) The higher $K_{\mathrm{m}}$ might also result from a charge difference; the diester has a charge of -1 , while a monoester, at the $\mathrm{pH}$ optimum for the PAP reaction, will be a mixture of monoanionic and dianionic forms. Whether the monoanion or the dianion is the substrate has not been determined, but it is possible that a monoester monoanion would be deprotonated upon coordination to the metal center, resulting in superior binding as the dianion, a possibility not open to a diester.

JA072647Q 